\title{
The degree of availability of the standards of the national framework for academic qualifications in early childhood in Jordan from the point of view of female teachers
}

\author{
Reda S. Al-Mawadiah ${ }^{1}$, Mohammad A. Al-Zu'bi ${ }^{1}$ \\ ${ }^{1}$ Department of Early Childhood, Faculty of Educational Sciences, Zarqa \\ University, Jordan
}




\title{
The degree of availability of the standards of the national framework for academic qualifications in early childhood in Jordan from the point of view of female teachers
}

\author{
Reda S. Al-Mawadiah ${ }^{1}$, Mohammad A. Al-Zu'bi ${ }^{{ }^{1} 1}$ \\ ${ }^{1}$ Department of Early Childhood, Faculty of Educational Sciences, Zarqa \\ University, Jordan
}

Received: 3rd May 2021 Revised: 29th May 2021 Accepted: 16th June 2021 DOI: https://doi.org/10.31559/CCSE2021.2.2.3

\begin{abstract}
:
Objective: The current study aimed to identify the most important Standards of the National Framework for Academic Qualifications (SNFAQ) in the Early Childhood Stage in Jordan. Methods: The study adopted a descriptive approach to achieve the aim of the study. Further, established a questionnaire for the degree of availability of the criteria for the SNFAQ in early childhood in Jordan. As the final form, the questionnaire consisted of three dimensions and (65) items. The current study sample consisted of 135 kindergarten teachers in the private and public sectors in Amman city. Results: The study results showed that the degree of availability of the SNFAQ in early childhood curricula in Jordan came with a medium degree, with a mean (2.82) and a standard deviation (0.61). Moreover, they attributed no statistically significant differences in the degree of availability of the SNFAQ in the early childhood stage in Jordan to kindergarten type and experience.

Furthermore, statistically significant differences in the degree of availability of the SNFAQ in Early Childhood in Jordan due to academic qualification favor those with postgraduate qualifications. Finally, a set of recommendations were made in light of the results of the study, including Increasing the interest of officials in the Ministry of Education, including leaders of kindergartens, about the importance of the SNFAQ, identifying an executive body to follow up on the inclusion of standards, and conducting studies similar to the current research on kindergarten departments in Jordanian universities.
\end{abstract}

Keywords: National Framework for Academic Qualifications; Early Childhood; Kindergarten Female Teachers.

${ }^{*}$ Corresponding author Mohammad A. Al-Zu'bi

Department of Early Childhood, Faculty of Educational Sciences, Zarqa University, Jordan E-mail: malzubi@zu.edu.jo 
International Journal of Childhood, Counselling, \& Special Education (CCSE), Volume2, Issue2, June: 2021, pp.103-112

\section{Introduction}

Global developments in education systems and their diversity have led to a clear and deep understanding of the academic qualifications provided by the various educational programs issued by the various educational institutions in Jordan. Therefore, it has become important to ensure that educational programs that lead to a certain level of qualifications achieve the same level of learning outcomes regardless of the educational institution in which the study took place, in addition to the need to link educational outcomes with the requirements of society and to proper planning of human resources at the level of the national, which can only be achieved by the existence of a frame of reference that precisely defines the levels of qualifications and their outputs and controls their quality.

Accordingly, System No. (9) of 2019 issued the "National Qualifications Framework" system published by Paragraph C of Article (7) of the Law on Accrediting Higher Education Institutions and Quality Assurance No. (20) of 2007, which represents a main reference for all educational institutions and service providers Training and quality assurance institutions as well as for graduate employers. The National Qualifications Framework consists of several levels with distinct learning descriptors, representing educational stages, types of degrees, or groups of experience. These descriptors are comprised of three main elements: knowledge, skills, and competencies (Alaboudi, 2019).
Therefore, there are global plans similar to the Qualifications Framework. One of these plans is the European Qualifications Framework (EQF), which aims for various educational reforms and aims to enhance and direct learning outcomes. Another plan is the National Qualifications Framework of the Russian Federation (NQFRF), the purpose of which is to improve learning outcomes by moving to the concept of "competency" from the idea of "qualification" (Mitrofanova, Mitrofanova \& Simonova, 2019).

Besides, the Jordan National Qualifications Fund (JNQF) was prepared and established by the Accreditation and Quality Assurance Authority for Higher Education Institutions (AQACHEI) in 2017. The JNQF consists of four main components (Harasees, 2017; Kanan \& Al-Bashaireh, 2019):

1. Levels: Ten levels have been defined for the framework, starting with the pre-school stage and ending with a doctoral qualification.

2. Classification of Educational Institutions: It includes the classification of educational institutions that award qualifications.

3. Framework Criteria: It consists of a set of standards, such as standards for residential qualifications and standards for the recognition of informal qualifications.

4. Guides: These include a guide to designing educational programs 
International Journal of Childhood, Counselling, \& Special Education (CCSE), Volume2, Issue2, June: 2021, pp.103-112

leading to qualifications and a guide to quality assurance of qualifications.

According to the Accreditation and Quality Assurance Authority for Higher Education Institutions (AQACHEI), the National Qualifications Fund (JNQF) is defined as a hierarchical classification of all levels and types of qualifications and certifications associated with formal and non-formal education programs, in which descriptors are defined for each level to identify the knowledge, skills, and competencies that must be related to the qualification (Accreditation and Quality Assurance Authority for Higher Education Institutions, 2019). The National Qualifications Fund depends on learning outcomes. This requires that the educational institutions establish their educational programs based on learning products to be compatible with the standard descriptors required to accommodate the academic qualifications resulting from these programs. In addition, to develop learning outcomes; Early childhood curricula must be standardized as there is a clear difference between these institutions in terms of outcomes in educational institutions (Kanaan and Al-Bashayra, 2019).

From this point of view, the Ministry of Education has determined that the early childhood stage will become a mandatory stage of education starting from 2020/2021, and this means they need to pay attention to early childhood learning outcomes by working to unify the frames of reference for early childhood learning outcomes by the application of The National
Framework for Academic Qualifications.

\section{Problem Statement:}

Jordanian education reforms, in general, are considered among the things that must be implemented through timely plans to contain the emerging and urgent changes that appear. Consequently, the Jordanian government has begun to implement education reforms through strategic plans that keep pace with developments, as these plans aim to develop education in the Kingdom. Where these plans are made by focusing on linking two basic processes: inputs and results. In addition, the strategic plan for the implementation of the Jordanian National Qualifications Framework (JNQF) for the years 2019. 2023 serves as a cornerstone for education reform in Jordan; To develop and enhance human capabilities (AlKharabsha, 2018).

Based on the preceding, the problem of the current study is determined by the degree of availability of the standards of the National Framework for Academic Qualifications in Early Childhood in Jordan. Thus, it is possible to define the problem of the current study by the following main question: What is the degree of availability of the national framework standards for academic qualifications in early childhood in Jordan from the point of view of teachers?

The following sub-questions emerge from the main question:

What is the degree of availability of the national framework standards for academic qualifications in early 
International Journal of Childhood, Counselling, \& Special Education (CCSE), Volume2, Issue2, June: 2021, pp.103-112

childhood curricula in Jordan from teachers' point of view?

1. Are there statistically significant differences at the significance level $(\alpha \leq 0.05)$ between the responses of the study sample members to the degree of availability of the national framework standards for academic qualifications in early childhood in Jordan from the point of view of the teachers due to the type of kindergarten?

2. Are there statistically significant differences at the significance level $(\alpha \leq 0.05)$ between the responses of the study sample members to the degree of availability of the national framework standards for academic qualifications in early childhood in Jordan from the point of view of the teachers due to experience and academic qualification?

3. Are there statistically significant differences at the significance level $(\alpha \leq 0.05)$ between the responses of the study sample members to the degree of availability of the national framework standards for academic qualifications in early childhood in Jordan from the point of view of the teachers due to the academic qualification?

\section{Objectives of the study:}

1. Identifying the most important standards of the National Framework for Academic Qualifications in Early Childhood in Jordan.

2. Identifying the estimates of the study sample members on determining the degree of availability of the national framework standards for academic qualifications in early childhood.

3. Identifying the differences between the responses of the study sample members about the degree of availability of the national framework standards for academic qualifications in early childhood due to the type of kindergarten, experience, and educational qualification.

\section{Significance of study:}

The current study derives its importance from the following:

1. Practical importance: The availability of the national framework standards in the early childhood specialization curriculum leads to the unification of learning outcomes in early childhood curricula in Jordan.

2. Through the findings and recommendations regarding the availability of national framework standards for academic qualifications in early childhood curricula, we will be able to achieve justice in achieving early childhood learning outcomes.

\section{Conceptual and procedural definitions:}

National Academic Qualifications Framework: The National Qualifications Framework consists of several levels with distinct learning descriptors that may represent educational levels, types of degrees, or levels of experience. These descriptors are comprised of three main components: knowledge, skills, and competencies. The various degrees and certificates are then classified according to the compatibility 
International Journal of Childhood, Counselling, \& Special Education (CCSE), Volume2, Issue2, June: 2021, pp.103-112

of the learning outcomes for each degree or certificate with the descriptors of the level to be placed in that degree. The placement process also includes ensuring the quality of the qualification by examining the compatibility of its outputs and the teaching and learning process with clear standards of quality assurance related to that level of learning. The National Qualifications Framework consists of ten levels, and these levels were determined after a survey of all types of qualifications that currently exist.

Early childhood stage: procedurally defined as the age stage between (2-6) years approximately.

Early childhood teachers: procedurally know that they are responsible for raising a group of children in the early childhood stage and bringing them up and taking their hands towards adaptation and growth, including providing them with diverse experiences and skills, commensurate with their different characteristics at this age stage (Tolbah, 2004).

\section{Methods}

The current study used the descriptive approach with its known limits by identifying the degree of availability of the national framework standards for academic qualifications in early childhood in Jordan from teachers' point of view. The researchers also attributed the reason for choosing the descriptive approach for the current study due to the suitability of this approach to the nature and objectives of the present study.
The study population and its sample:

The current study population consisted of all private and governmental kindergarten teachers in the Hashemite Kingdom of Jordan. The number of private and public kindergarten teachers in the Hashemite Kingdom of Jordan was (770) female teachers, depending on the data of the Ministry of Education. For data collection, a stratified random sample was used, where 135 kindergarten teachers for both the public and private sectors in the capital Amman were selected from the study population, where the number of female teachers from the government sector was 109 , while the number of female teachers from the private sector was (26).

\section{Instrumentation:}

To collect data from the study sample and to achieve the objectives of the current study, a questionnaire was used to determine the degree of availability of the national framework standards for academic qualifications in early childhood in Jordan, where the questionnaire in its final form consisted of three dimensions and (65) items as follows: Knowledge and information (29) items Skills (18) paragraphs, competencies (18) paragraphs.

A five-point Likert scale was used: strongly agree (5) points, agree (4) points, agree somewhat (3), disagree (2 points), strongly disagree (1 point). Thus, the lowest score will be (65) degrees, and the highest score will be (325). Therefore, the results are interpreted as follows: Low level: from 65-153 degrees, medium level: from 
International Journal of Childhood, Counselling, \& Special Education (CCSE), Volume2, Issue2, June: 2021, pp.103-112

154-241 degrees, high level: more than 241 degrees.

Reliability and validity of the questionnaire:

The researchers extracted the validity of the questionnaire's content by presenting it to a group of arbitrators specializing in childhood, education, and educational administration, where everyone agreed on the final version of the questionnaire with minor linguistic modifications in the paragraphs. Then, based on the arbitration of the arbitrators, the necessary amendment was made.

To verify the internal consistency of the questionnaire items; The tool was applied to an exploratory sample $(\mathrm{n}=$ 30) parameters which were randomly selected from within the study population, and they were not included in the sample, where the Pearson correlation coefficient was calculated between the score of each of the questionnaire items and the total score of the questionnaire. Thus, the amount of (65) paragraphs is honest in measuring what was prepared for its measurement, as its correlation coefficients with the total score were statistically significant at the level of significance $(\alpha \leq 0.05)$, where the probabilistic values for them were less than the significance level $(\alpha \leq .05)$.

Besides, the reliability of the questionnaire was also verified using Cronbach's alpha equation for reliability on the same exploratory sample $(\mathrm{n}=30)$, and table No. (1) shows the results of the reliability of the questionnaire.

Table(1): Illustrates the reliability of the questionnaire

\begin{tabular}{lcc}
\hline Dimensions & Number of items & Cronbach-Alpha \\
\hline Knowledges \& & 29 & 0.92 \\
informations & & \\
Skills & 18 & 0.91 \\
Competencies & 18 & 0.92 \\
Overall & 65 & 0.94 \\
\hline
\end{tabular}

Through the previous Table, it is clear that the value of Cronbach's alpha coefficient was high for each of the dimensions of the questionnaire, as it was as follows: knowledge and information (0.92), skills (0.91), competencies (0.92). Furthermore, the value of Cronbach's alpha coefficient for the overall resolution was also (0.94). Table No. 1 illustrates this.

This means that the reliability coefficient of the questionnaire is high, and the questionnaire in its final form is distributable. Thus, the researchers have confirmed the validity and reliability of the questionnaire, making them fully confident in the validity of the questionnaire and its validity to analyse the results and answer the study questions.

\section{Findings and discussions:}

This part of the study includes a presentation and discussion of the results in light of the questions raised, as well as a discussion of the findings of the research and the recommendations emanating from it, as follows:

The first question: What is the degree of availability of the national framework 
International Journal of Childhood, Counselling, \& Special Education (CCSE), Volume2, Issue2, June: 2021, pp.103-112

standards for academic qualifications in early childhood curricula in Jordan from teachers' point of view?

To answer this question, the arithmetic means and standard deviations were calculated to the degree of availability of the National
Framework of Academic Qualifications standards in the early childhood curricula in Jordan from the point of view of the teachers, at the level of each major and college. Table No. (2) shows the results of that:

Table (2): Arithmetic averages and standard deviations of the degree to which the standards of the national framework for academic qualifications are available in early childhood curricula in Jordan from the point of view of female teachers

\begin{tabular}{lcccc}
\hline Dimensions & Means & sd & Rank & Degree \\
\hline Knowledges \& informations & 2.95 & 0.68 & 1 & Moderate \\
Skills & 2.72 & 0.69 & 2 & Moderate \\
Competencies & 2.7 & 0.67 & 3 & Moderate \\
Over all & 2.82 & 0.61 & - & Moderate \\
\hline
\end{tabular}

Table No. (2) Shows that the degree of availability of the National Framework Standards for Academic Qualifications in the early childhood curricula in Jordan from the female teachers' point of view came at a medium level, with a mean (2.82) and a standard deviation (0.61). The "knowledge and information" axis came in The first rank, with an arithmetic mean of (2.95) and a standard deviation of (0.68), with a medium degree, followed in the second place by the "skills" axis, with an arithmetic mean of (2.72) and a standard deviation (0.69), with a medium degree, while in the field of "competencies" ranked The latter, with an arithmetic mean of (2.70) and a standard deviation of (0.67), with a medium degree.

The second question: Are there statistically significant differences at the significance level $(\alpha \leq 0.05)$ between the responses of the study sample members to the degree of availability of the standards of the national framework for academic qualifications in early childhood in Jordan from the point of view of the teachers due to the type of kindergarten?

To answer the question, the following was done:

\section{First: Kindergarten type}

The t-test for independent samples was used to find out the significance of the differences in the degree of availability of the National Framework of Academic Qualifications standards in early childhood in Jordan from the point of view of the teachers according to the type of kindergarten and Table No. (3): 
International Journal of Childhood, Counselling, \& Special Education (CCSE), Volume2, Issue2, June: 2021, pp.103-112

Table (3): Results of the T-test for independent samples to see the significance of the differences in the degree of availability of the standards of the national framework for academic qualifications in early childhood in Jordan from the point of view of the teachers according to the type of kindergarten

\begin{tabular}{|c|c|c|c|c|c|c|c|}
\hline Dimensions & Type of KG & Number & Means & sd & F degree & $\mathrm{t}$ & P-value \\
\hline \multirow{2}{*}{$\begin{array}{l}\text { Knowledges \& } \\
\text { informations }\end{array}$} & Government & 109 & 2.94 & .69 & \multirow[t]{4}{*}{133} & 660 & 511 \\
\hline & Private & 26 & 3.03 & .64 & & .000 & .311 \\
\hline \multirow[t]{2}{*}{ Skills } & Government & 109 & 2.76 & .72 & & \multirow{2}{*}{1.269} & \multirow{2}{*}{.207} \\
\hline & Private & 26 & 2.57 & .50 & & & \\
\hline \multirow[t]{2}{*}{ Competencies } & Government & 109 & 2.71 & .71 & & \multirow[b]{2}{*}{.539} & \multirow[b]{2}{*}{.591} \\
\hline & Private & 26 & 2.63 & .50 & & & \\
\hline \multirow[t]{2}{*}{ Over all } & Government & 109 & 2.83 & .65 & & \multirow{2}{*}{.229} & \multirow{2}{*}{.819} \\
\hline & Private & 26 & 2.79 & .44 & & & \\
\hline
\end{tabular}

It is clear from the results contained in Table No. (3) that there are no statistically significant differences at the level of significance $(\alpha \leq 0.05)$ in the degree of availability of the National Framework for Academic Qualifications standards in early childhood in Jordan from the point of view of the teachers due to the type of kindergarten, where the value of $(\mathrm{T})$ calculated for the total $=(0.229)$, and for the axes (knowledge, information, skills, competencies), where the values of $(\mathrm{T})=(-0.660,1.269, \quad 0.539)$, respectively.

Second: Academic qualification

The (T) test for independent samples was used to find out the significance of the differences in the degree of availability of the National Framework of Academic Qualifications standards in early childhood in Jordan from the point of view of the female teachers according to the educational qualification and Table No. (4):

Table (4): Results of the T-test for independent samples to see the significance of the differences in the degree of availability of the standards of the national framework for academic qualifications in early childhood in Jordan from the point of view of the female teachers according to the educational qualification

\begin{tabular}{|c|c|c|c|c|c|c|c|}
\hline Dimensions & Certification & Number & Means & sd & F degree & $\mathrm{t}$ & P-value \\
\hline \multirow{2}{*}{$\begin{array}{l}\text { Knowledges } \\
\text { informations }\end{array}$} & Undergraduate & 96 & 2.86 & .63 & 133 & \multirow{2}{*}{-2.667} & \multirow{2}{*}{.009} \\
\hline & Postgraduate & 39 & 3.20 & .5 & & & \\
\hline \multirow[t]{2}{*}{ Skills } & Undergraduate & 96 & 2.56 & .52 & & \multirow{2}{*}{-4.708} & \multirow{2}{*}{.000} \\
\hline & Postgraduate & 39 & 3.13 & .87 & & & \\
\hline \multirow[t]{2}{*}{ Competencies } & Undergraduate & 96 & 2.58 & .53 & & \multirow{2}{*}{-3.391} & \multirow{2}{*}{.001} \\
\hline & Postgraduate & 39 & 3.00 & .87 & & & \\
\hline \multirow[t]{2}{*}{ Over all } & Undergraduate & 96 & 2.70 & .49 & & \multirow{2}{*}{-3.847} & \multirow{2}{*}{.000} \\
\hline & Postgraduate & 39 & 3.12 & .76 & & & \\
\hline
\end{tabular}

It is evident from the results in Table No. (4) that there are statistically significant differences at the level of significance $(\alpha \leq 0.05)$ in the degree of availability of the standards of the national framework for academic qualifications in early childhood in Jordan from the point of view of the parameters attributed to the academic qualification, where the value of $(\mathrm{T})$ 
International Journal of Childhood, Counselling, \& Special Education (CCSE), Volume2, Issue2, June: 2021, pp.103-112

Calculated for the total $=(-3.847)$, and for the axes (knowledge and information, skills, competencies), where the values of $(\mathrm{T})=(-2.667,-4.708$, -3.391), respectively, and in favor of those with postgraduate qualifications.

\section{Third: experience}

One-way analysis of variance was used to indicate the differences in the degree of availability of the National Framework of Academic Qualifications standards in early childhood in Jordan from the point of view of the female teachers according to experience and Table No. (5) shows that:

Table (5): One-way variance analysis for the significance of differences in the degree of availability of the national framework standards for academic qualifications in early childhood in Jordan from the point of view of female teachers according to experience

\begin{tabular}{|c|c|c|c|c|c|c|c|c|c|c|}
\hline Dimensions & Exp. & $\mathrm{Nu}$. & Means & sd & $\begin{array}{c}\begin{array}{c}\text { Source } \\
\text { variance }\end{array} \\
\end{array}$ & $\begin{array}{c}\text { Total } \\
\text { squares }\end{array}$ & $\begin{array}{l}\text { The degree } \\
\text { of freedom }\end{array}$ & $\begin{array}{l}\text { Average } \\
\text { squares }\end{array}$ & F & $\begin{array}{c}\mathrm{P} . \\
\text { value }\end{array}$ \\
\hline \multirow{3}{*}{$\begin{array}{l}\text { Knowledges \& } \\
\text { informations }\end{array}$} & $5-1$ & 43 & 2.85 & .57 & Between & .99 & \multirow{3}{*}{$\begin{array}{l}32 \\
34\end{array}$} & .49 & \multirow{3}{*}{1.06} & \multirow{3}{*}{0.35} \\
\hline & $10-6$ & 42 & 3.07 & .69 & Error & 62.13 & & .47 & & \\
\hline & $\begin{array}{l}11 \& \\
\text { above }\end{array}$ & 50 & 2.95 & .76 & Total & 63.13 & & & & \\
\hline \multirow[t]{3}{*}{ Skills } & $5-1$ & 43 & 2.60 & .46 & Between & 1.56 & \multirow{3}{*}{$\begin{array}{l}32 \\
34\end{array}$} & .76 & \multirow{3}{*}{1.61} & \multirow[b]{3}{*}{0.2} \\
\hline & $10-6$ & 42 & 2.69 & .75 & Error & 62.52 & & .47 & & \\
\hline & $\begin{array}{l}11 \& \\
\text { above }\end{array}$ & 50 & 2.85 & .78 & Total & 64.04 & & & & \\
\hline \multirow[t]{3}{*}{ Competencies } & $5-1$ & 43 & 2.68 & .58 & Between & .02 & \multirow{3}{*}{$\begin{array}{l}32 \\
34\end{array}$} & .01 & \multirow{3}{*}{.03} & \multirow{3}{*}{0.98} \\
\hline & $10-6$ & 42 & 2.71 & .69 & Error & 60.76 & & .46 & & \\
\hline & $\begin{array}{l}11 \& \\
\text { above }\end{array}$ & 50 & 2.70 & .74 & Total & 60.78 & & & & \\
\hline \multirow[t]{3}{*}{ Over all } & $5-1$ & 43 & 2.73 & .50 & Between & .47 & \multirow{3}{*}{32} & .24 & \multirow{3}{*}{.63} & \multirow[b]{3}{*}{0.54} \\
\hline & $10-6$ & 42 & 2.86 & .61 & Error & 49.88 & & .38 & & \\
\hline & $\begin{array}{l}11 \& \\
\text { above }\end{array}$ & 50 & 2.86 & .70 & Total & 50.35 & & & & \\
\hline
\end{tabular}

It is noticed from Table No. (5) that there are no statistically significant differences at the significance level $(\alpha \leq$ 0.05 ) in the degree of availability of the National Framework of Academic Qualifications Standards in Early Childhood in Jordan from the point of view of the female teachers due to experience, where the value of $(\mathrm{P})$ for the total $=(0.625)$, and for the axes (knowledge, information, skills, competencies), where the values of $(\mathrm{P})=$ (1.058, 1.610, 0.026), respectively.

\section{Recommendations and suggestions:}

In light of the findings of this study, we recommend the following:

1. Increasing the interest of officials in the Ministry of Education, including kindergarten leaders, the importance of the national framework for academic qualifications, and identifying an executive body to follow up on the inclusion of standards.

2. Second, providing educational and training courses for early childhood teachers and principals on the importance of the National Academic Qualifications Framework.

3. Conducting similar studies to the current study on kindergarten departments in Jordanian universities.

4. Conducting an evaluation study to analyze the content of early childhood curricula in terms of the availability of the standards of the national framework for academic qualifications.

5. 
International Journal of Childhood, Counselling, \& Special Education (CCSE), Volume2, Issue2, June: 2021, pp.103-112

\section{References:}

Alaboudi, S. (2019). Extent of the Possibility of Applying the Administrative Standards of the National American Association of the Educational and Early Care Programs and the Obstacles to Applying them to Kindergartens in the Capital Amman from the Standpoint of Headmistresses and Teachers (Unpublished Master thesis, Middle East University, Jordan).

Ababneh, S. (2015). Quality Performance Assessment of Faculty of Educational Sciences at the University Of Jordan Related to National Council for Accreditation of Teacher Education (NCATE) from the Perspective of Faculty Members. DIRASAT, 42(3): 767-785, https://doi.org/10.12816/0023888.

Harasees, W. (2017). The Degree of Kindergarten Teachers' Practice in Jordan for the Technical Aspect of National Quality Assurance Standards in Kindergartens from their Point of View. The Jordanian Association for Educational
Sciences, The Jordanian Educational Journal, 2(2): 253-276.

Kanan, A., \& Albashaireh, Z. (2019). Analytical Study to The Competency Exam Results - The Accuracy Level- of Math Students at Jordanian Universities. DIRASAT, 46(4): 423-432.

Mitrofanova, E. A., Mitrofanova, A. E., \& Simonova, M. V. (2019). Sectoral Framework of Qualifications as a Tool for the Integration of Educational and Business Spheres of Russia. In Sustainable Growth and Development of Economic Systems (pp. 275-296). Springer, Cham.

Chen, Y. S., Yang, C. C., \& Yang, Y. F. (2020). Higher Academic Qualifications, Professional Training and Operating Performance of Audit Firms. Sustainability, $\quad$ 12(3): $\quad$ 1254, https://doi.org/10.3390/su12031254.

Mehrotra, S. (2020). The National Skills Qualification Framework in India: The Promise and the Reality. 